\title{
KUALITAS FUNGSIONAL DAN KEPUASAN PASIEN TERHADAP PERAWAT DAN DOKTER GIGI DI RUMAH SAKIT
}

\author{
Functional Quality and Patients' Satisfaction with Nurses and Dentists at the Hospital \\ Afifa Nur Chabibah \\ PERSAKMI Surabaya, Indonesia \\ E-mail: afifanurc@gmail.com
}

\begin{abstract}
Background: The quality of healthcare is an important aspect to be implemented by hospitals as a healthcare facility. Doctors and nurses are human resources that directly provide services to patients. Interpersonal communication between physicians and nurses with patients may influence patients' satisfaction as an output of service quality.

Aim: This study aimed to identify the functional quality of nurses and dentists on patients' satisfaction at Dental Polyclinic of Dr. R. Sosodoro Djatikoesoemo Bojonegoro Hospital.

Method: This research was a quantitative descriptive and observational research. The data were gathered from 68 respondents. Primary data were collected through a questionnaire disseminated for patients at Dental Polyclinic from 14th to 26th of May 2018. The data were processed and analyzed by using $2 \times 2$ position matrix. Results: The results show that the functional quality of nurses is in quadrant IV $(3.18 ; 3.21)$, and functional quality of doctors is in quadrant II $(3.48 ; 3.46)$.

Conclusion: This study concludes the nurses' functional quality still must be improved and promoted to the patients regarding to their competence, assurance (3S application and nurse's hospitality), and empathy (nurses' tranquility) while overall dentists' functional quality (competence, assurance, and empahty) is maximized.
\end{abstract}

Keywords: dentists, functional quality, hospital, nurses, satisfaction

\section{ABSTRAK}

Latar Belakang: Mutu fasilitas kesehatan merupakan aspek penting yang harus dilaksanakan oleh fasilitas kesehatan termasuk rumah sakit. Dokter dan perawat merupakan salah satu sumberdaya yang secara langsung berhadapan dengan pasien dalam memberikan pelayanan sehingga komunikasi interpersonal dokter dan perawat dengan pasien dapat mempengaruhi kepuasan pasien yang merupakan output dari mutu pelayanan.

Tujuan: Penelitian ini bertujuan untuk mengidentifikasi penilaian kualitas fungsional pada perawat dan dokter gigi terhadap kepuasan pasien di Poli Gigi dan Mulut RSUD Dr. R. Sosodoro Djatikoesoemo Bojonegoro.

Metode: Penelitian ini termasuk penelitian deskriptif kuantitatif dan bersifat observasional. Responden yang digunakan dalam penelitian ini berjumlah 68 orang. Data primer dikumpulkan melalui kuesioner kepada pasien Poli Gigi dan Mulut pada tanggal 14-26 Mei 2018 kemudian diolah dan dianalisis dengan menggunakan matriks posisi $2 \times 2$.

Hasil: Hasil dari penelitian ini diketahui bahwa kualitas fungsional perawat yang berada pada kuadran IV $(3,18$; $3,21)$ dan kualitas fungsional dokter berada pada kuadran II $(3,48 ; 3,46)$.

Kesimpulan: Kesimpulan dari hasil penelitian ini adalah kualitas fungsional perawat masih harus ditingkatkan dan dikomunikasikan mutu pelayanannya terutama pada aspek competence, assurance (penerapan 3S dan keramahan perawat), dan empathy (ketenangan perawat dalam menjawab pasien), sedangkan kualitas fungsional dokter secara keseluruhan aspek (competence, assurance, dan empathy) telah berada pada posisi yang maksimal.

Kata Kunci: dokter gigi, kualitas fungsional, kepuasan, perawat, rumah sakit

\section{PENDAHULUAN}

Kesehatan merupakan hak asasi manusia dan salah satu unsur kesejahteraan yang diperoleh setiap warga negara. Definisi kesehatan menurut UU No. 36 Tahun 2009 Tentang Kesehatan, yaitu kesehatan merupakan keadaan sehat, baik secara fisik, mental, spiritual, maupun sosial yang memungkinkan setiap orang untuk hidup produktif secara sosial dan ekonomis. Setiap orang juga berhak untuk memperoleh pelayanan kesehatan yang aman, bermutu, dan terjangkau.

Mutu pelayanan kesehatan harus diperhatikan oleh fasilitas pelayanan kesehatan seiring dengan pesatnya perkembangan berbagai aspek kehidupan seperti sosial, ekonomi, pendidikan, dan teknologi yang meningkatkan tingginya tuntutan masyarakat terhadap pelayanan kesehatan yang berkualitas atau 
bermutu. Mutu pelayanan kesehatan merupakan tingkat atau derajat kesempurnaan penampilan pelayanan kesehatan untuk memenuhi kebutuhan dan harapan pelanggan yang akhirnya pada kepuasan pelanggan (Supriyanto and Wulandari, 2011). Kepuasan merupakan hasil akhir atau output dari proses pelayanan yang diberikan oleh fasilitas kesehatan seperti Rumah Sakit. Pasien yang puas terhadap layanan kesehatan cenderung mematuhi nasihat, setia, dan taat terhadap rencana pengobatan yang telah disepakati (Patandianan et al., 2017).

Menurut Supriyanto and Wulandari (2011) penilaian konsumen terhadap produk dapat dibagi menjadi 2 yaitu kualitas teknis (technical quality) dan kualitas fungsional (functional quality). Kualitas fungsional meliputi competency (reliability), responsiveness, assurance, empathy, communication, caring, dan tangible. Kualitas teknis berkaitan dengan aspek teknis medis, keperawatan, penunjang medis (laboratorium, gizi), dan pelayanan non medis/ non keperawatan (administrasi, parkir), sedangkan kualitas fungsional berkaitan dengan bagaimana pelayanan tersebut disampaikan (how to deliver) sehingga terkait dengan aspek komunikasi interpersonal antara petugas kesehatan dengan pasien. Meskipun yang ditawarkan adalah pelayanan kesehatan, namun proses pelayanan tersebut sangat membutuhkan kualitas komunikasi yang memadai dari setiap tenaga kesehatan yang bertugas.

Rumah sakit sebagai salah satu faktor pembangunan kesehatan di Indonesia dituntut wajib memberikan pelayanan kesehatan yang aman, bermutu, antidiskriminasi, dan efektif dengan mengutamakan kepentingan pasien sesuai dengan standar pelayanan Rumah Sakit. Pelayanan keperawatan atau rawat jalan merupakan salah satu pelayanan yang harus diselenggarakan rumah sakit sesuai dengan definisi rumah sakit menurut UU No. 44 Tahun 2009 Tentang Rumah Sakit, yaitu Rumah Sakit merupakan institusi pelayanan kesehatan yang menyelenggarakan pelayanan kesehatan perorangan secara paripurna yang menyediakan rawat inap, rawat jalan, dan gawat darurat. Rumah sakit dalam memberikan pelayanan kesehatan tentu memerlukan sumberdaya yang cukup dan memadai. Sumberdaya manusia merupakan salah satu peran utama dalam melayani pasien karena dengan dokter, perawat atau karyawan, pasien dapat berkomunikasi secara langsung dan terbuka (Abdurahman, Junaidi and Aminuyati, 2017).

Sumberdaya manusia (dokter dan perawat) merupakan salah satu faktor penting yang berhubungan dengan mutu pelayanan dan kepuasan pasien. Pelayanan dokter yang diterima oleh pasien memiliki hubungan dengan kepuasan pasien (Patandianan et al., 2017). Pelayanan Keperawatan merupakan komponen penting dalam memberikan pelayanan kesehatan yang dapat menentukan baik buruknya citra rumah sakit, oleh karena itu mutu pelayanan keperawatan merupakan daya ungkit yang besar dalam mutu pelayanan rumah sakit (Anggarawati and Sari, 2016).

Pada tahun 2017, capaian kepuasan pelanggan pada RSUD Dr. R. Sosodoro Djatikoesoemo Bojonegoro belum memenuhi Standar Pelayanan Minimal (SPM) yang ditetapkan dalam Keputusan Menteri Kesehatan Nomor 129 tahun
2008. Capaian kepuasan pasien pada instalasi rawat jalan yaitu $80,2 \%$ memiliki selisih yang paling besar dengan target $90 \%$ dalam SPM yaitu dengan selisih sebesar $9,8 \%$. Ketidak puasan terhadap pelayanan tersebut disebabkan karena beberapa faktor internal antara lain aspek dokter, aspek perawat, kecepatan layanan penunjang, dan aspek lainnya (Supriyanto and Wulandari, 2011).

Rumah sakit yang tidak memperhatikan keluhan dan kepuasan pelanggan akan berdampak pada penurunan minat pelanggan dalam menggunakan pelayanan tersebut sehingga akan berdampak pada penurunan kunjungan. Poli Gigi dan Mulut merupakan salah satu poli yang mengalami penurunan kunjungan, oleh karena itu peneliti tertarik untuk meneliti kualitas fungsional dari perawat dan dokter dalam memberikan pelayanan kepada pasien. Tujuan utama dari penelitian ini adalah untuk mengidentifikasi penilaian kualitas fungsional perawat dan dokter terhadap kepuasan pasien pada aspek competency, assurance, dan empathy. Hasil penelitian ini diharapkan dapat membantu rumah sakit untuk memperbaiki kualitas pelayanan yang diberikan dengan mengfokuskan pada aspek yang penting untuk segera diperbaiki.

\section{METODE}

Penelitian merupakan penelitian deskriptif kuantitatif dan bersifat observasional serta menggunakan desain penelitian cross sectional. Penelitian ini bertujuan untuk menganalisis penilaian dan kepuasan pasien terhadap kualitas fungsional perawat dan dokter di Poli Gigi dan Mulut RSUD Dr. R. Sosodoro Djatikoesoemo Bojonegoro. Populasi dalam penelitian ini adalah pasien Poli Gigi dan Mulut di Instalasi Rawat Jalan RSUD Dr. R. Sosodoro Djatikoesoemo Bojonegoro pada tanggal 14 sampai dengan 26 Mei 2018. Sampel dalam penelitian ini berjumlah 68 responden yang diambil dengan cara accidental sampling dengan kriteria inklusi yaitu (1) Pasien yang sadar dan $\geq 12$ tahun yang mampu mengutarakan pendapatnya, apabila pasien berusia $<12$ tahun maka dapat diwakilkan keluarga atau wali yang bersangkutan. (2) Pasien yang telah selesai melakukan pelayanan di Poli Gigi dan Mulut serta hendak pulang atau menunggu pengambilan obat dengan asumsi pasien telah merasakan pelayanan di Poli Gigi dan Mulut.. Kriteria ekslusi yaitu (1) Pasien yang tidak bersedia menjadi responden. (2) Pasien yang tidak sadar atau tidak mampu mengutarakan pendapatnya. (3) Pasien yang melakukan pelayanan kontrol terhadap pelayanan yang telah dilakukan sebelumnya.

Data yang digunakan dalam penelitian ini adalah data primer yang diambil dengan kuesioner yang telah diuji validitas dan reliabilitasnya. Data primer dengan kuesioner digunakan untuk menilai kualitas fungsional perawat dan dokter pada aspek competency, assurance, dan empathy terhadap kepuasan yang dirasakan pasien. Analisis data dilakukan dengan membuat tabel skor dan mengitung nilai mean pada setiap atribut serta menghitung mean komposit sebagai nilai batas (cut off point) (Supriyanto and Wulandari, 2011). Hasil mean penilaian dan mean kepuasan pada setiap atribut kemudian dibandingkan dan dimasukkan kedalam matriks posisi $2 \times 2$ yang terbagi kedalam 4 kuadran. 
Apabila nilai mean komposit temasuk dalam kategori sangat puas maka dapat menjamin loyalitas pelanggan terhadap produk, sedangkan apabila mean komposit pasien termasuk dalam kategori cukup puas maka masih terdapat kemungkinan bahwa pasien akan memilih fasilitas kesehatan lain atau berpaling dari fasilitas kesehatan tersebut (Supriyanto and Wulandari, 2011).

\section{HASIL DAN PEMBAHASAN}

\section{Karakteristik Responden}

RSUD Dr. R. Sosodoro Djatikoesoemo Bojonegoro merupakan rumah sakit kelas B Non Pendidikan. Data karakteristik responden meliputi faktor demografi dan faktor sosial ekonomi ditunjukkan pada Tabel 1.

Karakteristik responden berdasarkan faktor demografi terbagi menjadi umur dan jenis kelamin. Karakteristik responden berdasarkan umur dikelompokkan menjadi 7 kelompok umur dari usia kanak-kanak hingga lansia akhir. Karakteristik responden berdasarkan umur yaitu mayoritas responden merupakan pasien remaja akhir yang berusia 16-25 tahun (33,8 \%). Kelompok umur yang paling banyak kedua yaitu responden dengan kelompok umur 26-35 tahun (22,1\%) yang termasuk dalam kategori dewasa awal. Karakteristik responden apabila dilihat berdasarkan jenis kelamin, yaitu lebih dari setengah dari jumlah total responden merupakan responden yang berjenis kelamin perempuan $(60,3 \%)$. Karakteristik responden berdasarkan faktor ekonomi terbagi menjadi jenis pekerjaan dan tingkat pendidikan responden. Jenis pekerjaan responden yaitu mayoritas responden adalah tidak bekerja $(48,5 \%)$. Jenis pekerjaan terbanyak kedua yaitu pasien dengan pekerjaan swasta $(29,4 \%)$.

Mayoritas responden tidak bekerja dikarenakan mayoritas responden masih berusia remaja, selain itu berdasarkan hasil wawancara, perempuan yang berusia 26-35 tahun rata-rata tidak bekerja dan sebagai ibu rumah tangga. Karakteristik responden berdasarkan tingkat pendidikan terbagi menjadi 6 kelompok tingkat pendidikan. Tingkat pendidikan responden mayoritas adalah tamat SMA $(49,2 \%)$.

Tabel 1. Karakteristik Responden di Poli Gigi dan Mulut RSUD Dr. R. Sosodoro Djatikoesoemo Bojonegoro tanggal 14-26 Mei 2018

\begin{tabular}{lcc}
\multicolumn{1}{c}{ Variabel } & Frekuensi & Persentase (\%) \\
\hline Faktor Demografi & & 4,4 \\
Usia & 3 & 7,4 \\
$5-11$ (kanak-kanak) & 5 & 33,8 \\
$12-16$ (remaja awal) & 23 & 22,1 \\
$16-25$ (remaja akhir) & 15 & 16,2 \\
$26-35$ (dewasa awal) & 11 & 14,7 \\
$36-45$ (dewasa akhir) & 10 & 1,5 \\
$46-55$ (lansia awal) & 1 & 39,7 \\
$56-65$ (lansia akhir) & & 60,3 \\
Jenis kelamin & 27 & 48,5 \\
Laki- laki & 41 & 5,9 \\
Perempuan & & 29,4 \\
Faktor Sosialekonomi & & 16,2 \\
Jenis pekerjaan & 33 & 0,0 \\
Tidak Bekerja & 4 & 1,5 \\
PNS & 20 & 9,2 \\
Swasta & 11 & 4,6 \\
Wiraswasta & 0 & 13,8 \\
TNI/POLRI & & 49,2 \\
Tingkat pendidikan & 100 \\
$\quad$ Tidak Sekolah & 1 & 21,5 \\
Masih SD & 6 & \\
Tamat SD & 3 & \\
Tamat SMP & 9 & \\
Tamat SMA & 32 & \\
Tamat PT & 14 & \\
\hline Total Responden & 68 & \\
\hline Sumber : Data Primer & & \\
\hline
\end{tabular}

Sumber : Data Primer

\section{Penilaian dan Kepuasan terhadap Kualitas Fungsional Perawat}

Perhitungan kualitas fungsional perawat dilakukan dengan memberikan skor dan mean pada aspek competency, assurance,dan empathy. Nilai Penilaian kualitas fungsional perawat oleh pasien pada tabel 2 menunjukkan nilai mean komposit 3,18 sedangkan kepuasannya menunjukkan nilai mean komposit sebesar 3,21 yang memiliki arti mean didapatkan dari hasil pembagian skor dengan jumlah responden yaitu sebesar 68 . Hasil perhitungan penilaian kualitas fungsional perawat di Poli Gigi dan Mulut ditunjukkan pada Tabel 2.

bahwa pasien memiliki penilaian yang cukup baik dan cukup puas terhadap kualitas fungsional perawat.

Penilaian pasien terhadap kualitas fungsional perawat menunjukkan terdapat 2 aspek penilaian perawat yang berada dibawah nilai mean komposit 
perawat, yaitu penerapan 3S perawat dan keramahan perawat dalam memberikan pelayanan kepada pasien, sedangkan 6 aspek lainnya yaitu telah berada di atas nilai mean komposit.

Kepuasan pasien terhadap perawat menunjukkan terdapat 2 aspek yang berada di bawah nilai mean komposit, yaitu kecekatan dan penerapan 3 S perawat. 6 aspek lainnya telah berada di atas nilai mean komposit kepuasan terhadap perawat.

Tabel 3 menunjukkan bahwa niai mean komposit dari penilaian pasien adalah 3,48 yang temasuk dalam kategori sangat baik dan nilai mean komposit dari kepuasan adalah 3,46 yang termasuk dalam kategori sangat puas. Terdapat 3 aspek yang nilai mean-nya berada dibawah nilai mean dokter, yaitu pada aspek keterampilan dokter, keramahan dokter, dan ketenangan dokter dalam menanggapi keluhan pasien. Sedangkan 5 aspek lainnya telah berada diatas nilai mean dokter.

Pada kepuasan kualitas fungsional dokter, diketahui terdapat 2 aspek yang nilai mean-nya berada dibawah niali mean komposit, yaitu pada empathy tentang ketenangan dokter dalam menanggapi keluhan dan sikap dokter memperhatikan pasien saat pasien berbicara. Adapun enam aspek lainnya telah berada di atas nilai mean dokter.

Nilai koordinat variabel kualitas fungsional perawat dan dokter ditunjukkan pada Tabel 4. Nilai mean dari perawat dan dokter kemudian dirata-rata dan digunakan sebagai nilai cut off point perawat dan dokter.

Tabel 2. Penilaian dan Kepuasan Kualitas Fungsional Perawat di Poli Gigi dan Mulut RSUD Dr. R. Sosodoro Djatikoesoemo Bojonegoro tanggal 14-26 Mei 2018

\begin{tabular}{|c|c|c|c|c|}
\hline \multirow[t]{2}{*}{ Aspek } & \multicolumn{2}{|c|}{ Penilaian } & \multicolumn{2}{|c|}{ Kepuasan } \\
\hline & ¿Skor & Mean & $\sum$ Skor & Mean \\
\hline \multicolumn{5}{|l|}{ Competency } \\
\hline Keterampilan perawat & 222 & 3,26 & 224 & 3,29 \\
\hline Kecekatan perawat & 217 & 3,19 & 214 & 3,15 \\
\hline \multicolumn{5}{|l|}{ Assurance } \\
\hline Penerapan 3S perawat & 167 & 2,46 & 166 & 2,44 \\
\hline Keramahan perawat & 212 & 3,12 & 225 & 3,31 \\
\hline Kesopanan tutur bahasa perawat & 232 & 3,41 & 234 & 3,44 \\
\hline Sikap perawat menghormati pasien & 231 & 3,40 & 232 & 3,41 \\
\hline \multicolumn{5}{|l|}{ Empathy } \\
\hline Ketenangan perawat menjawab pertanyaan & 221 & 3,25 & 221 & 3,25 \\
\hline Sikap perawat memperhatikan pasien berbicara & 228 & 3,35 & 228 & 3,35 \\
\hline Mean perawat & & 3,18 & & 3,21 \\
\hline
\end{tabular}

Tabel 3. Penilaian dan Kepuasan Kualitas Fungsional Dokter Gigi di Poli Gigi dan Mulut RSUD Dr. R. Sosodoro Djatikoesoemo Bojonegoro tanggal $14-26$ Mei 2018

\begin{tabular}{|c|c|c|c|c|}
\hline \multirow[t]{2}{*}{ Aspek } & \multicolumn{2}{|c|}{ Penilaian } & \multicolumn{2}{|c|}{ Kepuasan } \\
\hline & Skor & Mean & $\sum$ Skor & Mean \\
\hline Competency & & & & \\
\hline Keterampilan dokter & 234 & 3,44 & 236 & 3,47 \\
\hline Kecekatan dokter & 242 & 3,56 & 236 & 3,47 \\
\hline Assurance & & & & \\
\hline Penerapan 3S dokter & 237 & 3,49 & 236 & 3,47 \\
\hline Keramahan dokter & 236 & 3,47 & 237 & 3,49 \\
\hline Kesopanan tutur bahasa dokter & 238 & 3,50 & 238 & 3,50 \\
\hline Sikap dokter menghormati pasien & 237 & 3,49 & 236 & 3,47 \\
\hline Empathy & & & & \\
\hline Ketenangan dokter manggapi keluhan pasien & 231 & 3,40 & 232 & 3,41 \\
\hline Sikap dokter memperhatikan pasien saat berbicara & 238 & 3,50 & 231 & 3,40 \\
\hline Mean dokter & & 3,48 & & 3,46 \\
\hline
\end{tabular}

Tabel 4 menunjukkan nilai koordinat pada aspek competence, assurance, dan empathy baik pada perawat maupun dokter. Nilai mean penilaian dan kepuasan pada tabel 2 dan tabel 3 digunakan sebagai nilai koordinat pada matriks posisi. Nilai mean dari perawat dan dokter kemudian dihitung rata-ratanya dan digunakan sebagai nilai cut off point perawat dan dokter dalam matriks posisi. Berikut merupakan gambar matriks posisi yan ditunjukkan pada Gambar 1.
Gambar 1 menjelaskan bahwa mean dari kualitas fungsional dokter dan perawat terbagi ke dalam 2 kuadran, yaitu kuadaran II dan kuadran IV. Kuadran II merupakan posisi yang diinginkan yaitu dimana pasien telah memberikan penilaian yang sangat baik dan merasa sangat puas dengan pelayanan yang diberikan. Kuadran IV merupakan pelayanan yang dianggap oleh pasien masih harus ditingkatkan dan diperbaiki.

Aspek competence, assurance, dan empathy dokter telah berada pada kuadran IV, yaitu pasien 
menilai bahwa pelayanan yang diberikan dokter telah maksimal yaitu sangat baik dan dapat memberikan kepuasan kepada pasien. Aspek assurance perawat (kesopanan tutur bahasa perawat dan sikap perawat menghormati pasien) dan empati (sikap perawat memperhatikan pasien saat berbicara) juga berada pada kuadran II yang dinilai telah sangat baik dan memberikan kepuasan bagi pasien.

Terdapat 5 aspek yang terdapat dalam kuadran IV yang berarti bahwa produk memiliki penilaian dan kepuasan yang masih berada di bawah nilai mean komposit yaitu aspek competence perawat (keterampilan dan kecekatan perawat), assurance perawat (penerapan 3S perawat), dan empathy perawat (ketenangan dalam menjawab pertanyaan pasien).
Kualitas fungsional terkait dengan proses penyampaian pelayanan kepada pasien, yaitu terkait dengan aspek komunikasi interpersonal antara pasien dengan perawat dan pasien dengan dokter. Kualitas fungsional berpengaruh terhadap kepuasan pelanggan yaitu semakin baik kualitas fungsional yang diberikan oleh rumah sakit maka pelanggan akan merasa semakin puas terhadap pelayanan rumah sakit tersebut (Hidayat, 2014). Dengan demikian menunjukkan bahwa semakin baik aspek competence, assurance, dan empathy dokter maupun perawat akan semakin meningkatkan kepuasan dari pasien. Perilaku perawat dan dokter dalam memberikan pelayanan sangat penting untuk memberikan kepuasan pada pasien (Masqood et al., 2017).

Tabel 4. Nilai Koordinat Variabel Kualitas Fungsional

\begin{tabular}{lc}
\hline \multicolumn{1}{c}{ Variabel } & Mean \\
\hline Competency & 3,$26 ; 3,29$ \\
(C1) Keterampilan perawat & 3,$19 ; 3,15$ \\
(C2) Kecekatan perawat & 2,$46 ; 2,44$ \\
Assurance & 3,$12 ; 3,31$ \\
(A1) Penerapan 3S perawat & 3,$41 ; 3,44$ \\
(A2) Keramahan perawat & 3,$40 ; 3,41$ \\
(A3) Kesopanan tutur bahasa perawat & \\
(A4) Sikap perawat menghormati pasien & 3,$25 ; 3,25$ \\
Empathy & 3,$35 ; 3,35$ \\
(E1) Ketenangan perawat menjawab pertanyaan & 3,$44 ; 3,47$ \\
(E2) Sikap perawat memperhatikan pasien berbicara & 3,$56 ; 3,47$ \\
\hline Competency & \\
(C3) Keterampilan dokter & 3,$49 ; 3,47$ \\
(C4) Kecekatan dokter & 3,$47 ; 3,49$ \\
Assurance & 3,$50 ; 3,50$ \\
(A5) Penerapan 3S dokter & 3,$49 ; 3,47$ \\
(A6) Keramahan dokter & \\
(A7) Kesopanan tutur bahasa dokter & 3,$40 ; 3,41$ \\
(A8) Sikap dokter menghormati pasien & 3,$50 ; 3,40$ \\
Empathy & 3,$33 ; 3,33$ \\
(E3) Ketenangan dokter manggapi keluhan pasien & \\
(E4) Sikap dokter memperhatikan pasien saat berbicara &
\end{tabular}

Kompetensi merupakan kemampuan tenaga kesehatan (dokter dan perawat) untuk memberikan pelayanan yang diharapkan dengan akurat sesuai dengan janji yang diberikan oleh Rumah Sakit. Kompetensi berkaitan dengan kemampuan tenaga kesehatan dalam memberikan pelayanan kepada pasien dalam proses pelayanan. RSUD Dr. R. Sosodoro Djatikoesoemo Bojonegoro memiliki visi yaitu Menjadi Rumah Sakit Pilihan dan Unggulan di Bidang Pelayanan Medik Spesialistik dengan 6 nilai yang ditanamkan, salah satunya adalah Profesionalisme berdasarkan Profil RSUD Dr. R. Sosodoro Djatikoesoemo Bojonegoro (2017). Profesionalisme merupakan salah satu nilai yang dijanjikan oleh RSUD Dr. R. Sosodoro Djatikoesoemo Bojonegoro yaitu dengan menjaga dan meningkatkan profesionalisme tenaga kesehatan seperti dokter dan perawat. Pasien telah menilai bahwa kompetensi dokter telah dinilai sangat baik dan sangat memuaskan. Dokter yang berkompeten akan memberikan pelayanan yang bermutu.

Keterampilan dan keahlian perawat dalam menangani keluhan pelanggan dan profesionalismenya berpengaruh terhadap kepuasan pelanggan (Hidayat, 2014). Kompetensi perawat di Poli Gigi dan Mulut RSUD Dr. R. Sosodoro Djatikoesoemo Bojonegoro telah dinilai cukup baik dengan kepuasan cukup puas meskipun nilai mean-nya berada dibawah nilai mean komposit, hal ini dikarenakan nilai mean komposit dari pelayanan sangat tinggi dan termasuk dalam kategori sangat puas, sehingga rendahnya nilai kompetensi perawat bukan semata-mata rendah, melainkan karena nilai mean komposit yang tinggi dan dapat mengindikasikan bahwa pasien telah loyal dengan pelayanan yang diberikan (Supriyanto and Wulandari, 2011). Petugas kesehatan yang berkopetensi akan dapat meminimalkan kesalahan yang terjadi selama perawatan pasien, sehingga 
dapat menciptakan suatu kepercayaan dari pasien (Tanudjaya, 2014).

Perawat dapat meningkatkan kepuasan pelanggan salah satunya adalah dengan meningkatkan komitmen perawat untuk membentuk iklim yang dapat memuaskan pelanggan. Kompetensi perawat tidak semata-mata dapat berpengaruh langsung terhadap kualitas layanan, tetapi juga dapat berpengaruh tidak langsung melalui variabel lain yaitu komitmen perawat (Muhith and Nurwidji, 2014). Penciptaan iklim yang dapat memuaskan pelanggan harus didukung dengan komunikasi yang baik antara dokter dan perawat. Peningkatan komunikasi antara dokter dan perawat sangat terkait dengan pengurangan kesalahan dalam praktik, mengurangi infeksi nosokomial, dan meningkatkan kepuasan pasien (Kadda, 2013). Penerapan program untuk meningkatkan komitmen perawat dalam memberikan pelayanan yang bermutu harus ditingkatkan oleh rumah sakit.
Assurance merupakan kemampuan pemberi jasa untuk menimbulkan rasa percaya pelanggan terhadap jasa yang ditawarkan. Assurance dapat berkaitan dengan pengetahuan, keramahan, kesopanan, dan sifat-sifat yang dapat dipercaya yang dimiliki para staf (Supriyanto and Wulandari, 2011). Keramahan dan kesopanan dokter telah dinilai sangat baik dan sangat memuaskan oleh pasien. Dokter telah memberikan pelayanan yang ramah karena sebagian pasien mengatakan telah mengenal dokter yang melayaninya, sehingga pasien merasa mudah saat berkomunikasi dengan dokter. Dokter juga telah dianggap sopan karena dokter mampu menjaga privasi dan menggunakan tutur bahasa yang santun dan halus. Selain itu dokter juga memberikan senyuman dan sapaan saat sebelum melayani pasien. Dokter gigi spesialis anak juga selalu memberikan hadiah kepada pasien anak agar anak-anak tidak takut untuk memeriksakan giginya ke dokter.

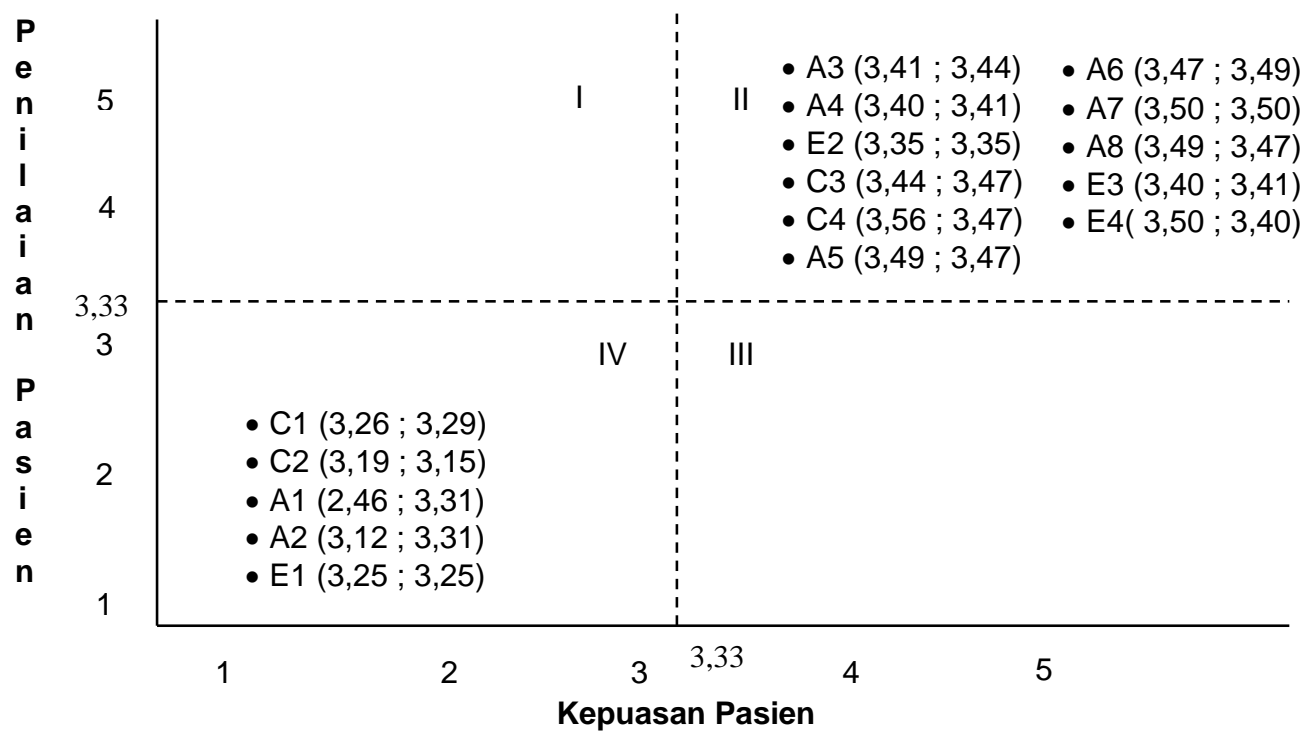

Gambar 1. Matriks Posisi Penilaian dan Kepuasan Kualitas Fungsional Perawat dan Dokter di Poli Gigi dan Mulut RSUD Dr. R. Sosodoro Djatikoesoemo Bojonegoro

Kesopanan tutur bahasa perawat, serta kesopanan perawat dengan menghargai pasien telah dinilai pasien dengan sangat baik dan sangat memuaskan. Perawat selalu menggunakan bahasa yang santun kepada pasien baik dengan bahasa Krama Inggil maupun bahasa Indonesia tergantung dari responden. Kesopanan perawat dengan menghargai pasien ditunjukkan dengan sikap perawat yang sama kepada semua pasien dengan tidak membeda-bedakan pasien berdasarkan jenis pembayaran, etnis, agama, maupun ras pasien.

Keramahan perawat termasuk dalam kategori sangat baik dan sangat puas meskipun nilai meannya berada dibawah mean komposit, sedangkan penerapan $3 S$ perawat dan keramahan perawat dinilai cukup baik meskipun demikian pasien sudah merasa sangat puas. Penerapan $3 S$ perawat dirasa cukup oleh pasien, namun sebaiknya penerapan 3S perawat ditingkatkan untuk meningkatkan kualitas pelayanan ayng diberikan. Kesopanan dan keramahan petugas (dokter dan perawat) menunjukkan bahwa pelayanan yang diberikan merupakan pelayanan yang diberikan termasuk baik. Keramahan dan kesopanan merupakan salah satu ciri pelayanan yang baik (Abdurahman, Junaidi and Aminuyati, 2017).

Empati (empathy) merupakan pemberian pelayanan secara individual dengan penuh perhatian dan sesuai dengan kebutuhan pasien (Supriyanto and Wulandari, 2011). Petugas mau mendengarkan keluhan dan membantu pasien serta petugas yang tidak acuh merupakan pelayanan 
yang diharapkan pasien. Empati adalah memberikan perhatian yang tulus dan bersifat individual atau pribadi yang diberikan petugas kepada pasien dengan upaya untuk memahami keinginan pasien (Abdurahman, et al., 2017). Pasien akan merasa puas dengan kualitas pelayan apabila perawat dan dokter meluangkan waktunya untuk merespon dan mendengarkan apa yang diinginkan pasien dengan peduli (Masqood et al., 2017).

Perhatian dokter yaitu pada aspek ketenangan dokter dalam menanggapi keluhan pasien dan perhatian dokter saat pasien berbicara telah dinilai sangat baik dan sangat memuaskan oleh pasien. Dokter telah menanggapi keluhan atau pertanyaan yang diajukan pasien dengan sangat tidak tergesa-gesa dan dengan tenang menjawab atau menanggapi keluhan pasien. Dokter memberikan perhatian kepada pasien dengan cara memotivasi, memberikan saran dan masukan kepada pasien mengenai kesehatan gigi dan mulut pasien. Pasien telah merasa sangat mendapat perhatian oleh dokter saat diperiksa atau diberikan tindakan dan dapat memuaskan pasien. Dokter gigi yang memberikan perhatian dan menunjukkan sikap kepedulian yang tulus terhadap keluhan pasien pada akhirnya akan menimbulkan kepuasan pasien pada pelayanan yang diberikan (Sembel, Opod and Hutagalung, 2014). Empati dokter harus dipertahankan sehingga memberikan kepuasan kepada pasien. Konsumen yang merasa mendapatkan empati dari petugas akan merasa tidak ragu untuk tetap mengkonsumsi jasa yang diberikan sehingga akan membentuk tingkat loyalitas pelanggan (Tanudjaya, 2014).

Empati perawat yaitu ketenangan perawat dalam menjawab atau menanggapi pertanyaan pasien telah dinilai cukup baik cukup puas oleh pasien, sedangkan perhatian perawat saat pasien berbicara telah dinilai sangat baik dan pasien telah merasa sangat puas. Perawat memperhatikan pasien saat pasien berbicara atau menyampaikan pertanyaan sehingga pasien merasa puas, namun saat perawat menanggapi atau menjawab pertanyaan dilakukan bersamaan dengan menulis pada kartu medis pasien atau administrasi lainnya sehingga pasien tidak memberikan nilai maksimal terhadap ketenangan perawat menjawab atau menanggapi pertanyaan pasien. Perilaku perawat dan dokter dalam memberikan pelayanan harus ditingkatkan karena apabila pelayanan yang dokter dan perawat selalu menimbulkan kepuasan bagi pasien, maka pasien akan memberikan respon baik dengan kembali mengunjungi rumah sakit apabila membutuhkan pelayanan (Masqood et al., 2017).

Secara keseluruhan, kualitas fungsional pada aspek competence, assurance, dan empathy dokter serta assurance perawat (kesopanan tutur bahasa dan sikap menghormati pasien) telah berada pada posisi yang diinginkan, yaitu memberikan kepuasan yang maksimal, sedangkan kualitas fungsional perawat pada aspek competence, assurance (penerapan 3S dan keramahan perawat), serta empathy masih harus diinformasikan kepada pelanggan dan segera meningkatkan atau memperbaiki mutu pelayanan sehingga dapat meningkat sama dengan kualitas fungsional dokter. Meskipun demikian, nilai mean komposit $(3,40 ; 3,39)$ termasuk dalam kategori sangat puas. Hal tersebut dibuktikan dengan tingginya apresiasi atau penilaian yang diberikan oleh pasien untuk masing-masing indikator kualitas fungsional (competence, assurance, dan empathy).

Nilai mean komposit mendekati sangat puas adalah nilai yang menjamin terjadi loyalitas pasien, sedangkan nilai mean komposit puas menunjukkan kemungkinan pasien akan kembali atau kemungkinan meninggalkan atau tidak mau kembali apabila membutuhkan pelayanan di lain waktu (Supriyanto and Wulandari, 2011). Dengan demikian dapat disimpulkan bahwa RSUD Dr. R. Sosodoro Djatikoesoemo Bojonegoro, khususnya dokter dan perawat di Poli Gigi dan Mulut telah mampu memberikan kualitas fungsional yang baik

\section{SIMPULAN}

Kualitas fungsional dokter secara keseluruhan aspek (competence, assurance, dan empathy) telah berada pada posisi yang diinginkan sehingga perlu dipertahankan mutunya. Hanya terdapat 3 aspek pada kualitas fungsional perawat yang telah berada pada posisi yang diharapkan yaitu assurance (kesopanan tutur bahasa dan sikap menghormati pasien) dan empathy (sikap perawat memperhatikan pasien berbicara). Kualitas fungsional perawat secara umum masih harus ditingkatkan mutu pelayanannya serta diinformasikan ke pelanggan terutama pada aspek competence, assurance (penerapan 3S dan keramahan perawat), serta empathy (ketenangan perawat dalam menjawab pasien).

Peningkatan competence perawat dapat dilakukan dengan memberikan pelatihan dan peningkatan keterampilan guna meningkatkan komitmen dalam menciptakan iklim pelayanan yang memuaskan. Meningkatkan penerapan 3S pada perawat dengan dengan cara memasukkan aspek 3S kedalam SOP pelayanan di Poli Gigi dan Mulut serta mengsosialiasaikan pembaharuan SOP. Sesama staf dalam poli Gigi dan Mulut juga dapat saling mengingatkan untuk menerapkan $3 S$ sesuai dengan nilai yang terdapat di RSUD Dr. R. Sosodoro Djatikoesoemo Bojonegoro, yaitu keramahan.

Peningkatan empati perawat dapat dilakukan dengan lebih meningkatkan perhatian saat pasien menyampaikan keluhan dan memberikan tanggapan atau umpan balik kepada pelanggan dengan tidak tergesa-gesa dan memberikan pasien waktu lebih banyak untuk menjelaskan keadaannya maupun pertanyaannya.

\section{DAFTAR PUSTAKA}

Abdurahman, Junaidi and Aminuyati (2017) 'Analisis Kualitas Pelayanan Jasa Kesehatan (pada Pasien Rawat Inap Rumah Sakit Pendidikan Universitas Tanjungpura Pontianak)', Jurnal Pendidikan dan Pembelajaran Universitas 
Tanjungpura, 6(2), pp. 1-22. Available at: http://jurnal.untan.ac.id/index.php/jpdpb/articl e/view/18439/15563.

Hidayat, R. (2014) 'Pengaruh kualitas fungsional, kualitas teknik dan citra terhadap kepuasan pelanggan rumah sakit', Jurnal Ekonomi dan Keuangan, 18(2), pp. 139-164. Available at: https://anzdoc.com/pengaruh-kualitasfungsional-kualitas-teknik-dan-citraterha.html.

Kadda, O. (2013) 'Effective Physician - Nurse communication', Health Science Journal, 7(3), pp. 237-238. Available at: http://www.hsj.gr/medicine/effectivephysician--nurse-communication.pdf

Kementerian Kesehatan Republik Indonesia (2008) 'Keputusan Menteri Kesehatan Republik Indonesia Nomor: 129/Menkes/Sk/li/2008 tentang Standar Pelayanan Minimal Rumah Sakit Menteri Kesehatan Republik Indonesia', Kementerian Kesehatan Republik Indonesia.

doi: 10.1017/CBO9781107415324.004

Kementerian Kesehatan Republik Indonesia (2009) 'Undang-Undang Republik Indonesia Nomor 44 Tahun 2009 Tentang Rumah Sakit', Kementerian Kesehatan Republik Indonesia, p. 40.

doi: 10.1017/CBO9781107415324.004.

Kementerian Kesehatan RI (2009) 'Undang-Undang Republik Indonesia Nomor 44 Tahun 2009 Tentang Rumah Sakit', Kementerian Kesehatan Republik Indonesia, p. 40. doi: 10.1017/CBO9781107415324.004.

Mubashra Maqsood, Humera Maqsood, Robina kousar, Chanda jabeen, Ali Waqas, P. D. S. A. G. (2017) 'Effects of hospital service quality on patients satisfaction and behavioural intention of doctors and nurses', Saudi Journal of Medical and Pharmaceutical Sciences, 3(6B), pp. 556567. doi: $10.21276 /$ sjmps.

Muhith, A. and Nurwidji (2014) 'Kualitas Layanan Keperawatan (Studi tentang Ruang Rawat Inap Rumah Sakit Di Mojokerto)', Jurnal Ners, 9(2), pp. 321-328. Available at: http://e-

journal.unair.ac.id/index.php/JNERS/article/vi ew/2688/1954.

Patandianan, R. et al. (2017) 'Hubungan Antara Pelayanan Dokter dan Pelayanan Perawat dengan Kepuasan Pasien di Ruang Rawat Inap Rumah Sakit Pancaran Kasih GMIM Manado', Jurnal IKMAS, 1(7), pp. 1-8. Available

at: www.ejournalhealth.com/index.php/ikmas/art icle/viewFile/170/164

RSUD Dr. R. Sosodoro Djatikoesoemo Bojonegoro (2017) Profil RSUD Dr. R. Sosodoro Djatikoesoemo Bojonegoro. Bojonegoro.

Supriyanto, S and Wulandari, R. D. (2011) Manajemen Mutu Pelayanan Kesehatan. Surabaya: Health Advocacy.

Sembel, M., Opod, H. and Hutagalung, B. S. P. (2014) 'Gambaran Tingkat Kepuasan Pasien
Terhadap Perawatan Gigi dan Mulut Di Puskesmas Bahu', e-GIGI, 2(2). Available at: http://ejournal.unsrat.ac.id/index.php/egigi/art icle/view/5855/5388.

Supriyanto, S. and Wulandari, R. D. (2011) Manajemen Mutu Pelayanan Kesehatan. I. Surabaya: Pohon Cahaya.

Tanudjaya, P. K. (2014) 'Pengaruh Kualitas Pelayanan Klinik Gigi Terhadap Kepuasan dan Kepercayaan Pasien Sehingga Meningkatkan Keinginan untuk Berobat Kembali', Jurnal Manajemen dan pemasaran jasa, 7(1), pp. 39-60.

Tuti Anggarawati, N. W. S. (2016) 'Kepentingan Bersama Perawat-Dokter dengan Kualitas Pelayanan Keperawatan', Jurnal IImiah Kesehatan Keperawatan, 12(1), pp. 44-54. Available at: https://ejournal.stikesmuhgombong.ac.id/ind ex.php/JIKK/article/view/139/130. 